\title{
A Study on Comparison of CK-MB, LDH and CRP Levels in Asphyxiated and Non-Asphyxiated Neonates
}

\author{
Meenakshi Waddankeri ${ }^{1}$, Rohit Bhandar ${ }^{2}$, Shrikant Waddankeri ${ }^{3}$ \\ ${ }^{1}$ Senior Resident, Department of Paediatrics, M R Medical College, Gulbarga, Karnataka, ${ }^{2}$ Associate Professor, Department of Paediatrics, M R Medical \\ College, Gulbarga, Karnataka, ${ }^{3}$ Consultant Paediatrician,Anugraha Child Guidance Clinic, Gulbarga, Karnataka.
}

\section{Abstract}

Background: Perinatal asphyxia is a common neonatal problem and contributes significantly to neonatal morbidity and mortality. Only a third of deliveries in India are institutional and many asphyxiated babies are brought late to hospitals. In the absence of perinatal records, it is difficult to retrospectively diagnose perinatal asphyxia. There is a need to identify neonates with asphyxia who will be at high risk for hypoxic ischemic encephalopathy and multi-organ dysfunction. Subjects and Methods: The study was conducted on 60 neonates comprising the cases and 30 neonates comprising the controls meeting the inclusion and exclusion criteria. The blood samples for CK-MB and CRP, LDH was drawn at $24 \pm 2$ and $72 \pm 2$ hours of age respectively y and sent for analysis. Result: CK-MB value of $>60 \mathrm{U} / \mathrm{L}$ was found to $43(71.7 \%)$ of cases, $\mathrm{LDH}>580 \mathrm{U} / \mathrm{L}$ was found in $40(66.7 \%)$ of cases and CRP $>1 \mathrm{mg} / \mathrm{dl}$ was found in 5(8.3\%) cases. Conclusion: CK-MB and LDH were found to be elevated in asphyxiated neonates compared to non asphyxiated neonates.

Keywords: Perinatal asphyxia; Creatine kinase muscle-brain fraction (CK-MB); Lactate dehydrogenase (LDH); C-reactive protein (CRP); hypoxic ischemic encephalopathy (HIE).

Corresponding Author: Dr. Meenakshi Waddankeri, Senior Resident, Department of Paediatrics, M R Medical College, Gulbarga, Karnataka.

Received: December 2019

Accepted: December 2019

\section{Introduction}

Perinatal asphyxia is a common perennial neonatal problem and contributes significantly to neonatal morbidity and mortality. Globally, hypoxia of the newborn (birth asphyxia) is estimated to account for $23 \%$ of the 4 million neonatal deaths and $26 \%$ of the 3.2 million stillbirths each year. ${ }^{[1]}$ An estimated 1 million children who survive birth asphyxia live with chronic neurodevelopmental morbidities - cerebral palsy, mental retardation, and learning disabilities. Every hour, 104 children die as aresult of asphyxia. ${ }^{[1]}$ That is, approximately $8 \%$ of the total global pediatric mortality (age less than five years) making it a serious problem. Due to a lack of resources, developing countries are worse off.

In India, between 250,000 to 350,000 neonates die each year due to birthasphyxia, mostly within the first three days of life. ${ }^{[2]}$ Data from National Neonatal Perinatal database (NNPD) suggests that perinatal asphyxia contributes to almost $20 \%$ of neonatal deaths in India. ${ }^{[2]}$ Ante-partum and intra-partum asphyxia contributes to asmany as 300,000 to 400,000 stillbirths. ${ }^{[2]}$ In India, $8.4 \%$ of inborn babies have a one minute Apgar score less than 7 and 1.4\% suffer from hypoxic ischemicencephalopathy (HIE). ${ }^{[2]}$ Accurate estimates of the proportion of neonatal mortality attributable to birth asphyxia are limited by the lack of a consistent definition for use in community-based settings and the absence of vital registration in communities where the majority of neonatal deaths occur.

Only a third of deliveries in India are institutional ${ }^{[3]}$ and many asphyxiated babies have a delayed presentation to hospitals. The signs of asphyxial injury are nonspecific and overlap with other illnesses. In the absence of perinatal records, it is difficult to retrospectively diagnose perinatal asphyxia.

Although asphyxia is associated with multiple organ injuries, especially with adverse neurological outcomes, management still focuses on supportive care. So, if the adverse effects of hypoxia on the newborn are considered, there is a need to identify infants who will be at high risk for hypoxic ischemic encephalopathy and early neonatal death as a consequence of perinatal hypoxia. A variety of markers have been examined to identify perinatal hypoxia including electronic fetal heart monitoring, low Apgar scores, cord $\mathrm{pH}$, electroencephalograms (EEG), computed tomography (CT) and magnetic resonance imaging (MRI) scans and Doppler flow studies. The current problem then is the inability to precisely distinguish the false positive affected from the true positive asphyxiated or compromised fetus. Several studies have been conducted to evaluate better markers that help distinguish an asphyxiated from a nonasphyxiated neonate.

Perinatal asphyxia may result in adverse effects on all major body systems. Many of these complications are potentially 
fatal. In a term infant with perinatal asphyxia renal, neurologic, cardiac and lung dysfunction occur in $50 \%$, $28 \%, 25 \%$ and $23 \%$ cases respectively ${ }^{4}$. The extent of multiorgan dysfunction (MOD) determines the early outcome of an asphyxiated neonate with either the neonate succumbing as a consequence of organ damage or recovering completely. Generally there are no long term sequelae associated with these organ system derangements.

HIE refers to the central nervous system (CNS) dysfunction associated with perinatal asphyxia.Transient myocardial ischemia (TMI) with myocardial dysfunction may occur in any neonate with a history of perinatal asphyxia. An elevated serum creatine kinase muscle-brain fraction (CK$\mathrm{MB}$ ) or cardiac troponin $\mathrm{T}$ (cTnT) level may be helpful in determining the presence of myocardial damage. An elevation of serum CK-MBfraction of $>5 \%$ to $10 \%$ may indicate myocardial injury. ${ }^{[5]}$

Myocardial damage may also be determined by 2D Echo changes in ejection fraction (EF), fractional shortening (FS), Mitral or tricuspid regurgitation, ventricular hypokinesia. ECG also may depict changes in ST segment, $\mathrm{T}$ wave and Q wavechanges. ${ }^{[6,7]}$

\section{Subjects and Methods}

Leakage of intracellular enzymes such as alanine aminotransferase (ALT), aspartate aminotransferase (AST) and lactate dehydrogenase (LDH) signaling multiorgan dysfunction is seen together with HIE after perinatal asphyxia.

Elevation in inflammatory mediators like interleukin 6, soluble intercellular adhesion molecule-1 and CRP is seen in stressful conditions like infection andperinatal asphyxia.

A sample of 60 neonates (>37 weeks) with perinatal asphyxia having base excess of $-12 \mathrm{mEq} / \mathrm{L}$ and above or atleast 1 non-specific sign of sickness- tachypnea, chest retractions, grunt, lethargy, poor feeding, hypotonia, irritability, central cyanosis, cardiac gallop rhythm, cardiac murmur, shock and abdominal distension who were born and admitted to Neonatal Intensive care unit attached to Medical College.Controls were chosen in a ratio of 2:1.

The study included two groups

\section{The case group}

It included 60 neonates fulfilling the following criteria

\section{$\underline{\text { Inclusion criteria }}$}

- Neonates [gestational age more than 37 weeks]Normal/LSCS born and admitted at NICU of BTGH or STGH.

- Neonates weighing more than 2000grams

- Apgar of less than or equal to 5 at one min or less than 7 five min of birth.

- Failure to establish spontaneous respiration.

- Base excess of $-12 \mathrm{mEq} / \mathrm{L}$ or above at the time of admission

\section{Exclusion criteria}

- $\quad$ Preterm neonates [gestational age < 36weeks].

- Neonates with internal congenital anomalies

- Neonates with syndromoid appearance.

- Neonates with congenital heart disease

- Neonates born at other than BTGH or STGH

- Neonates with birth weight of less than 2000 grams

\section{The control group}

It included 30 term apparently healthy neonates appropriate for gestational age without signs of perinatal asphyxia as evidenced by normal fetal heart rate patterns and one minute Apgar score $\geq 7$.

\section{Results}

Table 1: Shows gender distribution of neonates studied.

\begin{tabular}{|l|l|l|l|l|}
\hline \multirow{2}{*}{ Gender } & \multicolumn{2}{|l|}{ Cases $(\mathbf{n}=\mathbf{6 0})$} & \multicolumn{2}{l|}{ Controls $(\mathbf{n}=\mathbf{3 0})$} \\
\cline { 2 - 5 } & No & $\mathbf{\%}$ & No & \% \\
\hline Male & 36 & 60.0 & 17 & 57.0 \\
\hline Female & 24 & 40.0 & 13 & 43.0 \\
\hline Total & 60 & 100.0 & 30 & 100.0 \\
\hline
\end{tabular}

Among the 60 neonates in case group, there were $36(60 \%)$ males and $24(40 \%)$ females. Among the control group of 30 neonates, there were $17(57 \%)$ males and 13 (43\%) females. Gender distribution of neonates is statistically similar between two groups with $\mathrm{P}=0.993$.

Table 2: Shows comparison of cut-off levels of CK-MB , CRP and LDH in casesand controls.

\begin{tabular}{|c|c|c|c|c|c|c|c|}
\hline \multicolumn{2}{|c|}{ Variables } & \multicolumn{2}{|c|}{$\begin{array}{l}\text { Study } \\
\text { Group } \\
(\mathrm{N}=60)\end{array}$} & \multicolumn{2}{|c|}{$\begin{array}{l}\text { Control } \\
\text { Group } \\
(\mathbf{N}=\mathbf{3 0})\end{array}$} & \multirow[t]{2}{*}{$\begin{array}{l}\text { X2- } \\
\text { test } \\
\text { value }\end{array}$} & \multirow[t]{2}{*}{$\begin{array}{l}\text { P-Value \& } \\
\text { Significance }\end{array}$} \\
\hline & & No. & $\%$ & No. & $\%$ & & \\
\hline \multirow{2}{*}{$\begin{array}{l}\text { CK- } \\
\text { MB } \\
\text { U/L }\end{array}$} & $>60$ & 43 & 71.7 & 0 & 0 & \multirow{2}{*}{$\begin{array}{l}\mathrm{X} 2= \\
27.31\end{array}$} & \multirow{2}{*}{$\begin{array}{l}\mathrm{P}<0.001, \\
\text { VHS }\end{array}$} \\
\hline & $\leq 60$ & 17 & 28.3 & 30 & 100.0 & & \\
\hline \multirow{2}{*}{$\begin{array}{l}\text { CRP } \\
\mathrm{mg} / \mathrm{dl}\end{array}$} & $>1$ & 5 & 8.3 & 2 & 6.7 & \multirow{2}{*}{$\begin{array}{l}\mathrm{X} 2= \\
0.077\end{array}$} & \multirow{2}{*}{$\begin{array}{l}\mathrm{P}>0.05, \\
\mathrm{NS}\end{array}$} \\
\hline & $\leq 1$ & 55 & 91.7 & 28 & 93.3 & & \\
\hline \multirow{2}{*}{$\begin{array}{l}\mathrm{LDH} \\
\mathrm{U} / \mathrm{L}\end{array}$} & $\leq 580$ & 20 & 33.3 & 29 & 96.7 & \multirow{2}{*}{$\begin{array}{l}\mathrm{X} 2= \\
32.34\end{array}$} & \multirow{2}{*}{$\begin{array}{l}\mathrm{P}<0.001, \\
\text { VHS }\end{array}$} \\
\hline & $>580$ & 40 & 66.7 & 1 & 3.3 & & \\
\hline
\end{tabular}

Among the 60 neonates in the case group, 17 (28.33\%) had CK-MB levels <60 U/L and 43 (71.67\%) had CK-MB levels $>60 \mathrm{U} / \mathrm{L}$. In control group all had CK-MB levels <60 U/L. The number of neonates with CK-MB levels $>60 \mathrm{U} / \mathrm{L}$ is significantly more in cases when compared to controls with $\mathrm{P}<0.001$.

Among the 60 neonates in the case group, 20 (33.33\%) had LDH levels <580 U/L and 40 (66.7\%) had LDH levels >580 U/L. Of the 30 neonates in control group 29(96.7\%) had LDH levels <580 U/L and 1 (3.3\%) had LDH level >580 $\mathrm{U} / \mathrm{L}$. The number of neonates with $\mathrm{LDH}$ levels $>580 \mathrm{U} / \mathrm{L}$ is significantly more in cases when compared to controls with 
$\mathrm{P}<0.001$.

Among the 60 neonates in the case group, 5 (8.3\%) had CRP levels $>1 \mathrm{mg} / \mathrm{dl}$ and $55(91.7 \%)$ had CRP levels $<1 \mathrm{mg} / \mathrm{dl}$. Of the 30 neonates in control group $28(93.3 \%)$ had CRP levels $<1 \mathrm{mg} / \mathrm{dl}$ and $2(6.7 \%)$ had CRP level $>1 \mathrm{mg} / \mathrm{dl}$. There is no statistically significant difference in CRP levels among cases and control group $(p>0.05)$

Table 3: Shows comparison of CK-MB, CRP and LDH levels in cases and controls

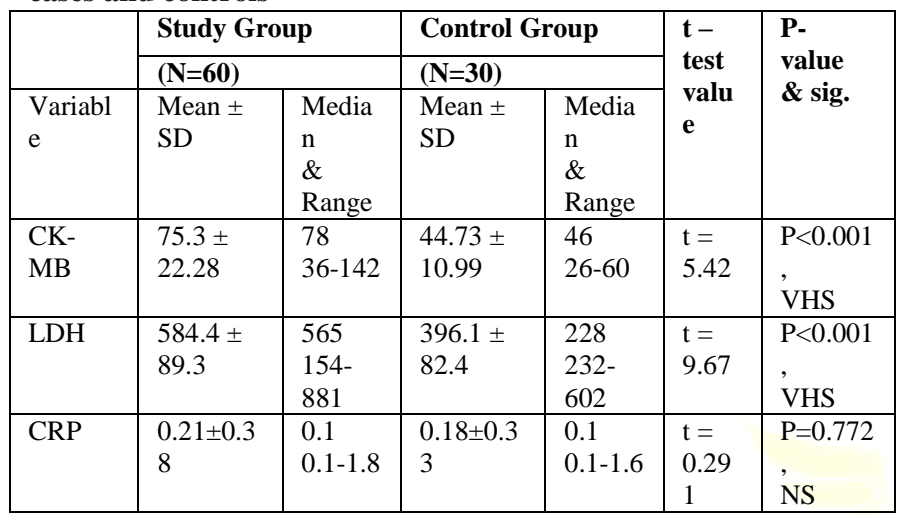

$\mathrm{NS}=$ not significant, $\mathrm{S}=$ significant, HS=highly significant, VHS=very highly significant

Mean value of CK-MB is $75.3 \mathrm{U} / \mathrm{L}$ in cases and $44.73 \mathrm{U} / \mathrm{L}$ in controls. Mean value of $\mathrm{LDH}$ is $584.4 \mathrm{U} / \mathrm{L}$ in cases and $396.1 \mathrm{U} / \mathrm{L}$ in controls. Mean value of CRP is $0.21 \mathrm{mg} / \mathrm{dl}$ in cases and $0.18 \mathrm{mg} / \mathrm{dl}$ in controls. Mean values if CK-MB and LDH are more in cases compared to controls $(\mathrm{p}<0.001)$. There is statistically no significant change in CRP values among two groups $(\mathrm{p}=0.77)$.

Table 4: Correlation of CK-MB, CRP and LDH with stages of HIE

\begin{tabular}{|c|c|c|c|c|c|c|}
\hline \multicolumn{2}{|c|}{ Variables } & \multicolumn{3}{|c|}{ HIE stages } & \multirow{2}{*}{$\begin{array}{l}\text { X2-test } \\
\text { value }\end{array}$} & \multirow{2}{*}{$\begin{array}{l}\text { P- } \\
\text { Value } \\
\text { \& sig }\end{array}$} \\
\hline & & $\begin{array}{l}\text { Mild } \\
\text { (1) }\end{array}$ & $\begin{array}{l}\text { Moderate } \\
\text { (2) }\end{array}$ & $\begin{array}{l}\text { Severe } \\
\text { (3) }\end{array}$ & & \\
\hline \multirow{2}{*}{$\begin{array}{l}\text { CK- } \\
\text { MB }\end{array}$} & $>60$ & 22 & 17 & 4 & \multirow[t]{2}{*}{$X 2=9.68$} & \multirow{2}{*}{$\begin{array}{l}\mathrm{P} \\
<0.001, \\
\text { VHS }\end{array}$} \\
\hline & $\leq 60$ & 16 & 1 & 0 & & \\
\hline \multirow[t]{2}{*}{ CRP } & $>1$ & 2 & 2 & 1 & \multirow[t]{2}{*}{$\mathrm{X} 2=1.27$} & \multirow{2}{*}{$\begin{array}{l}\mathrm{P} \\
=0.852, \\
\mathrm{NS}\end{array}$} \\
\hline & $\leq 1$ & 36 & 16 & 3 & & \\
\hline \multirow[t]{2}{*}{ LDH } & $>580$ & 19 & 17 & 4 & \multirow[t]{2}{*}{$\mathrm{X} 2=12.95$} & \multirow{2}{*}{$\begin{array}{l}\mathrm{P} \\
<0.001, \\
\text { VHS }\end{array}$} \\
\hline & $\leq 580$ & 19 & 1 & 0 & & \\
\hline
\end{tabular}

In neonates with mild HIE 22 cases had CK-MB >60U/L and 16 had CK-MB <60U/L. In neonates with moderate HIE 17 had CK-MB >60U/L and 1 had CK-MB <60U/L. In neonates with severe HIE all 4 had CK-MB >60U/L. Raised levels of CK-MB was significant in neonates with moderate and severe HIE $(\mathrm{p}<0.001)$.

\section{Discussion}

In the present study, gender distribution of neonates is statistically similarbetween two groups and the results are comparable to Reddy $\mathrm{S}$ et al. ${ }^{[8]}$ The incidence of birth asphyxia is more in males in both the studies. There is neither a previous study available on this aspect nor a plausible mechanism has been proposed for thesame. The social belief in the Indian setup that male babies are cared better and female babies are usually neglected and are managed at home even if they are very sick did not have any interference with the study population as none of the parents of the cases included in the study refused admission at birth. In the present study the number of neonates with CK-MB levels $>60 \mathrm{U} / \mathrm{L}$ is significantly more in cases when compared to controls with $\mathrm{P}<0.001 .28 .3 \%$ of the cases in the present study had CK-MB levels $>60 \mathrm{U} / \mathrm{L}$. This is comparable to Reddy Set al ${ }^{8}$ in which $36 \%$ of cases had CKMB levels $>60 \mathrm{U} / \mathrm{L}(\mathrm{P}=0.006)$.

In the present study the mean CK-MB levels were significantly higher in casescompared to controls with $\mathrm{P}<0.001$ which is comparable to Reddy $\mathrm{S}$ et $\mathrm{al}^{8}$ andRajakumar PS et al ${ }^{[9]}$

Raised levels of CK-MB among asphyxiated neonates was also observed instudies conducted by Primhaket $\mathrm{al}^{[10]}$, Omokhodion SI et $\mathrm{al}^{11}$, Fonseca $\mathrm{E}$ et $\mathrm{al}^{[12]}$,Barberi et $\mathrm{al}^{13} .66 .7 \%$ of the cases in the present study had LDH levels $>580 \mathrm{U} / \mathrm{L}$. This islower when compared to Reddy $\mathrm{S}$ et al ${ }^{8}$ in which $100 \%$ of cases had LDH levels $>580 \mathrm{U} / \mathrm{L}$. In both the studies, the number of neonates with LDH levels $>580 \mathrm{U} / \mathrm{L}$ is significantly more in cases when compared to controls. This is statistically significant in both the studies with $\mathrm{P}<0.001$.In the present study the mean LDH levels in cases were significantly higher in cases compared to controls with $\mathrm{P}<0.001$ which iscomparable to Reddy $\mathrm{S}$ et al..$^{[8]}$

In the present study CRP $>1 \mathrm{mg} / \mathrm{dl}$ was found only in $5(8.3 \%)$ of cases and $2(6.7 \%)$ of controls. There is no statistically significant difference in CRP levelsamong cases and controls. This is similar to study of Xanthouet $\mathrm{al}^{[14]}$ in which CRP levels were higher in infected neonates compared to asphyxiated neonates and controls.

\section{Conclusion}

- Estimation of CK-MB at 24 hours of life and LDH at 72 hours of life can help distinguish an asphyxiated from a non-asphyxiated term neonate.

- Raised levels of CK-MB, LDH was more significant in cases with moderate to severe HIE.

\section{References}

1. Lawn JE, Cousens S, Zupan J. Lancet Neonatal Survival Steering 
Team. 4 million neonatal deaths: When? Where? Why? Lancet 2005; 365 (9462):891 900 .

2. NNPD network. National Neonatal Perinatal Database- report for the year 2002-2003. NNF NNPD network. New Delhi: 2005.

3. Indian Institute of Population Studies. National Family Health Survey (NFHS-2) 1998-99. Mumbai: 2000.

4. Perlman JM, Tack ED, Martin T, Shackelford G, Amon E. Acute systemic organ injury in term infants after asphyxia. Am J Dis Child 1989;143:617-620.

5. Addock LM, Papile L. Perinatal asphyxia. In: Cloherty JP, Eichenwald EC, Stark AR, editors. Manual of neonatal care. 6th edition. Philadelphia: Lippincott Williams and Wilkins, a WoltersKluwar business; 2008: p.518-528.

6. Aleksandra M. Simovic, Sergej M. Prijic, et al Predictive value of biochemical, echocardiographic and electrocardiographic markers in non-surviving and surviving asphyxiated full-term newborns The Turkish Journal of Pediatrics 2014; 56: 243-249

7. P.S. Rajakumar, B. Vishnu Bhat, M.G. Sridhar . Electrocardiographic and Echocardiographic Changes in Perinatal Asphyxia. Indian Journal of Pediatrics, Volume 76-March, 2009

8. Reddy S, Dutta S, Narang A. Evaluation of Lactate Dehydrogenase, Creatine Kinase and Hepatic Enzymes for the Retrospective Diagnosis of Perinatal Asphyxia Among Sick Neonates. Indian Pediatrics February 17, 2008; 45: 144-147.

9. RajakumarPS,VishnuBhat B, Sridhar MG, Balachander J, Konar BC, Narayanan P, et al. Cardiac Enzyme Levels in Myocardial Dysfunction inNewborns with Perinatal Asphyxia. Indian Journal of Pediatrics December, 2008; 75:1223-1225.

10. Primhak RA, Jedeikin R, Ellis G, MakelaSK,Gillan JE, Swyer PR, et al. Myocardial ischaemia in asphyxia neonatorum. Electrocardiographic, enzymatic and histological correlations. ActaPediatrScand 1985; 74: 595-600.
11. Omokhodion SI, Losekoot TG, Jaiyesimi F. Serum creatine kinase and creatine kinase-MB isoenzyme activities in perinatally asphyxiated newborns.Eur Heart J. 1991 Sep;12(9):980-984.

12. Fonseca E, Garcia-Alonso A, Zarate A, Ochoa R, Galvan RE, Jimenez-Solis G. Elevation of activity of creatine phosphokinase (CK) and its isoenzymes in the newborn is associated with fetal asphyxia and risk at birth.ClinBiochem. $1995 \mathrm{Feb}$;28(1):91-5.

13. Barberi I, Calabro MP, Cordaro S, Gitto E, Sottile A, Prudente D, et al.Myocardial ischemia in neonates with perinatal asphyxia. Electrocardiographic, echocardiographic and enzymatic correlations.Eur J Pediatr 1999; 158: 742 $\neg 747$.

14. Xanthou M, Fotopoulos s, Mouchtouri A, Lipsou N, ZikaI,Sarafidou JInflammatory mediators in perinatal asphyxia and infection. ActaPaediatrSuppl 2002;91(438):92-7.

Copyright: (C) the author(s), 2019. It is an open-access article distributed under the terms of the Creative Commons Attribution License (CC BY 4.0), which permits authors to retain ownership of the copyright for their content, and allow anyone to download, reuse, reprint, modify, distribute and/or copy the content as long as the original authors and source are cited.

How to cite this article: Waddankeri M, Bhandar R, Waddankeri S. A Study on Comparison of CK-MB, LDH and CRP Levels in Asphyxiated and Non-Asphyxiated Neonates. Asian J.Clin.Pediatr. Neonatol.2019;7(4):38-41.

DOI: dx.doi.org/10.21276/ajcpn.2019.7.4.9

Source of Support: Nil, Conflict of Interest: None declared. 